\title{
Effects of rutin and buckwheat seeds on energy metabolism and methane production in dairy cows
}

\author{
Ann-Kathrin Stoldt, ${ }^{*}$ Michael Derno, ${ }^{*}$ Gürbüz Das, ${ }^{*}$ Joachim M. Weitzel,† Siegfried Wolffram,ł \\ and Cornelia C. Metges* \\ *Institute of Nutritional Physiology "Oskar Kellner," and \\ †Institute of Reproductive Biology, all of Leibniz Institute for Farm Animal Biology (FBN), 18196 Dummerstorf, Germany \\ łlnstitute of Animal Nutrition and Physiology, Christian-Albrechts University of Kiel, 24118 Kiel, Germany
}

\section{ABSTRACT}

Flavonoids are secondary plant metabolites with several health promoting effects. As dairy cows often suffer from metabolic imbalance and health problems, interest is growing in health improvements by plant substances such as flavonoids. Our group has recently shown that the flavonoids quercetin and rutin (a glucorhamnoside of quercetin) are bioavailable in cows when given via a duodenal fistula or orally, respectively, affect glucose metabolism, and have beneficial effects on liver health. Furthermore, flavonoids may reduce rumen methane production in vitro through their antibacterial properties. To test the hypothesis that rutin has effects on energy metabolism, methane production, and production performance in dairy cows, we fed rutin trihydrate at a dose of $100 \mathrm{mg} / \mathrm{kg}$ of body weight to a group of 7 lactating dairy cows for $2 \mathrm{wk}$ in a crossover design. In a second experiment, 2 cows were fed the same ration but were supplemented with buckwheat seeds (Fagopyrum tartaricum), providing rutin at a dose comparable to the first experiment. Two other cows receiving barley supplements were used as controls in a change-over mode. Blood samples were taken weekly and respiration measurements were performed at the end of each treatment. Supplementation of pure rutin, but not of rutin contained in buckwheat seeds, increased the plasma quercetin content. Methane production and milk yield and composition were not affected by rutin treatment in either form. Plasma glucose, $\beta$-hydroxybutyrate, and albumin were increased by pure rutin treatment, indicating a possible metabolic effect of rutin on energy metabolism of dairy cows. In addition, we did not show that in vivo ruminal methane production was reduced by rutin. In conclusion, we could not confirm earlier reports on in vitro methane reduction by rutin supplementation in dairy cows in established lactation.

Received July 20, 2015.

Accepted December 1, 2015.

${ }^{1}$ Corresponding author: metges@fbn-dummerstorf.de
Key words: dairy cow, rutin, quercetin, methane, metabolism

\section{INTRODUCTION}

Flavonoids belong to the large group of secondary plant metabolites with phenolic structures (Formica and Regelson, 1995; Nijveldt et al., 2001). Flavonoids have been reported to have various health-promoting effects due to their antiviral, antibacterial, anti-inflammatory, and antihepatotoxic properties. Quercetin, as one of the best described flavonoids in plants, is mainly bound to sugars forming glycosides, such as rutin, whereas quercetin aglycone is bound to rutinose (Nijveldt et al., 2001). Rutin is one of the most consumed flavonoids in human nutrition and is found, for example, in tea and buckwheat (Formica and Regelson, 1995; Materska, 2008). Interest is growing in the use of plant-derived substances as a potential natural alternative to using synthetic agents and pharmaceuticals to improve animal health and productivity (Materska, 2008; Rochfort et al., 2008).

In view of the beneficial effects flavonoids have in humans and rodents (Panchal et al., 2011; Galleano et al., 2012), increasing interest has been noted in possible health benefits among dairy cows by plant bioactive compounds and, in particular, flavonoids. Associated with the onset of high milk production, dairy cows experience negative energy balance often followed by metabolic imbalances and health problems. Our group has recently shown that quercetin contained in rutin is much more bioavailable in cows compared with quercetin aglycone when administered intraruminally (Berger et al., 2012), whereas quercetin aglycone requires administration via a duodenal fistula to be systemically available (Gohlke et al., 2013a). Some beneficial effects on performance (Guo et al., 2010), glucose metabolism, as well as milk composition (Gohlke et al., 2013b) and liver health (Stoldt et al., 2015) were reported in dairy cows. Furthermore, it is known from other species that flavonoids affect energy, in particular glucose and lipid 
metabolism (Hoek-van den Hil et al., 2013; Wein and Wolffram, 2014).

Some in vitro studies using pure flavonoids (Oskoueian et al., 2013; Seradj et al., 2014) or plants rich in flavonoids (Wang et al., 2013; Niderkorn and Macheboeuf, 2014) revealed the potential to reduce methane production without negative effects on fermentation processes (Oskoueian et al., 2013; Berger et al., 2015). Flavonoids have been shown to alter the rumen microbiome and to reduce the population of protozoa and methanogenic bacteria (Santra et al., 2012; Oskoueian et al., 2013), which is presumably the underlying mechanism of reduced methane production. Methane is a potent greenhouse gas with enormous climatewarming potential (Etim et al., 2013), and ruminant livestock is an important contributor to anthropogenic methane emission (Pitesky et al., 2009). Furthermore, methane production by rumen microbes implies loss of gross energy for the cow. Thus, a potential reduction in methane production by flavonoids would be environmentally favorable.

To investigate whether selected flavonoids affect health, energy metabolism, and methane emission in dairy cows, we conducted a feeding trial with rutin including indirect calorimetry gas exchange measurements (Derno et al., 2009). Because quercetin is largely degraded by rumen microbes when given orally (Berger et al., 2012), we chose rutin as a likely rumen-protected source of quercetin (Berger et al., 2012) for supplementation. Given that buckwheat has a high rutin content (Fabjan et al., 2003) and is suitable as feed for ruminants (Amelchanka et al., 2010; Kälber et al., 2012), we also tested whether supplementation of tartary buckwheat (Fagopyrum tartaricum) seeds have properties comparable to pure rutin isolate. We hypothesized that oral supplementation of rutin as a pure substance or via buckwheat seeds would have beneficial effects on energy metabolism, methane production, and milk yield and composition in dairy cows in established lactation.

\section{MATERIALS AND METHODS}

\section{Animals and Diet}

The study was conducted in compliance with the German animal protection regulations with approval of the authorities of the land Mecklenburg-Vorpommern, Germany (Landesamt für Landwirtschaft, Lebensmittelsicherheit und Fischereiwesen Mecklenburg-Vorpommern, Germany; LALLF M-V/TSD/7221.3-2.1-019/12).

In the study, 7 German Holstein cows with $>7,000$ $\mathrm{kg}$ of milk in their first lactation and an average BW of $608 \pm 14 \mathrm{~kg}$ (mean $\pm \mathrm{SE}$ ) were monitored over a
Table 1. Ingredients and chemical composition $(\mathrm{g} / \mathrm{kg}$ of DM, unless otherwise noted) of TMR diet (means)

\begin{tabular}{|c|c|}
\hline Item & Measurement \\
\hline \multicolumn{2}{|l|}{ Ingredient } \\
\hline Grass silage & 173 \\
\hline Corn silage & 332 \\
\hline Straw & 34.9 \\
\hline Grass hay & 38.9 \\
\hline Corn (ground) & 79.5 \\
\hline Soybean meal & 19.9 \\
\hline Rapeseed meal & 20.1 \\
\hline Sugar beet pulp ${ }^{1}$ & 37.7 \\
\hline Concentrate $^{2}$ & 256 \\
\hline Minerals $^{3}$ & 8.9 \\
\hline Feed lime & 4.5 \\
\hline \multicolumn{2}{|l|}{ Chemical composition } \\
\hline $\mathrm{DM}\left(\mathrm{g} / \mathrm{kg}\right.$ of $\left.\mathrm{FM}^{4}\right)$ & 508 \\
\hline Crude ash & 67 \\
\hline $\mathrm{CP}$ & 161 \\
\hline $\mathrm{NDF}$ & 343 \\
\hline Crude fat & 30 \\
\hline $\mathrm{ME}^{5}(\mathrm{MJ} / \mathrm{kg}$ of $\mathrm{DM})$ & 11.2 \\
\hline $\mathrm{NE}_{\mathrm{L}}{ }^{5}(\mathrm{MJ} / \mathrm{kg}$ of $\mathrm{DM})$ & 7 \\
\hline
\end{tabular}

${ }^{1}$ Arp, (Thordsen, Rautenberg GmbH \& Co. KG, Sollerupmühle, Germany): 7.3 MJ of $\mathrm{NE}_{\mathrm{L}} / \mathrm{kg}$ of $\mathrm{DM}$ and, $153 \mathrm{~g}$ of utilizable protein/ $\mathrm{kg}$ of DM.

${ }^{2}$ Concentrate MF 2000 (Vollkraft Mischfutterwerke GmbH, Güstrow, Germany): $33 \%$ extracted soy meal, $20 \%$ corn, $17 \%$ wheat gluten, $8 \%$ extracted rapeseed meal, $5 \%$ sugar beet pulp, $2 \%$ sodium hydrogen carbonate, $1.3 \%$ calcium carbonate, $0.2 \%$ sodium chloride, 8.0 MJ of $\mathrm{NE}_{\mathrm{L}} / \mathrm{kg}$ of DM, and $204 \mathrm{~g}$ of utilizable protein $/ \mathrm{kg}$ of DM.

${ }^{3}$ Rinderstolz 9522 lactation (Salvana Tiernahrung GmbH, Sparrieshoop, Germany): $92 \%$ crude ash, $20 \%$ calcium, $5 \%$ phosphorus, $6 \%$ magnesium, $8 \%$ sodium, and $0.03 \%$ retinol, $0.06 \% \beta$-carotene, $0.0005 \%$ 25-OH-vitamin $\mathrm{D}_{3}$, and $0.40 \%$ DL- $\alpha$-tocopherolacetate.

${ }^{4} \mathrm{FM}=$ fresh matter.

${ }^{5}$ Calculated as recommended by the German Society of Nutrition Physiology (GfE, 2004).

period of 4 wk starting on d 100 of the second lactation. The cows were kept in tiestalls, had free access to water, and were offered a TMR for ad libitum intake. The diet composition was calculated in accordance to recommendations of the German Society of Nutritional Physiology (GfE, 2004). Chemical composition of the TMR was determined according to Weender standard procedure (Naumann and Bassler, 1993) and is shown together with the feed components in Table 1. The DMI and milk yield were recorded daily, milking time was daily at 0630 and $1630 \mathrm{~h}$.

Cows were fed a TMR only (control) or with daily supplementation of $100 \mathrm{mg}$ of rutin trihydrate (Carl Roth GmbH, Karlsruhe, Germany) per kilogram of BW for a period of $2 \mathrm{wk}$ in a crossover design, resulting in a 4-wk experimental period. The rutin dose used was based on the results of a previous study of our group (Berger et al., 2012). Subsequently, in a second experiment, 2 of the cows received the same TMR plus 
$6.5 \mathrm{~g} / \mathrm{kg}$ of BW tartary buckwheat seeds (Fagopyrum tartaricum; Deutsche Saatveredelung AG, Lippstadt, Germany) daily for 2 wk with a rutin content of $1.54 \%$ $\mathrm{DM}$, which is equivalent to $100 \mathrm{mg}$ of rutin $/ \mathrm{kg}$ of BW. Seeds were ground to a particle size of $3 \mathrm{~mm}$. Two control cows received an equal amount of barley for the same period of time in a change-over mode. For both supplements, daily amounts were divided into 2 equal portions, given at 0730 and $1630 \mathrm{~h}$, and mixed into a small amount of TMR before regular feed submission.

\section{Respiration Measurements}

During the last $2 \mathrm{~d}$ of each 2 -wk treatment (rutin or TMR), cows were transferred to open-circuit respiration chambers (Derno et al., 2009) for 48-h measurements of components of energy expenditure. On the first day of measurement, cows were fed ad libitum. On the second day, residual feed was taken away at $0630 \mathrm{~h}$ and cows were not fed again until $1630 \mathrm{~h}$ (restrictive feeding) to expose cows to a metabolic challenge, as we suspected that flavonoid effects could be more pronounced under challenging conditions. Cows were fed again with TMR ad libitum.

Cows were acclimated to the chambers several times before the experiment until they started eating, laying down, and ruminating in the chamber. In the afternoon before the first day of respiration measurement, cows were placed in the chambers and were provided with their respective rations. Drinking water was freely available the entire time.

Gas exchange measurements were started at $0700 \mathrm{~h}$ on each respiration day. Concentrations of $\mathrm{CO}_{2}, \mathrm{O}_{2}$, and $\mathrm{CH}_{4}$ were measured at 6 -min intervals throughout 23.9 $\mathrm{h}$ and data were normalized to $24 \mathrm{~h}$. Feed intake and physical activity were measured continuously for each cow individually, and production of $\mathrm{CO}_{2}$ and $\mathrm{CH}_{4}$ as well as consumption of $\mathrm{O}_{2}$ was calculated as described previously (Derno et al., 2013). Within the respiration chamber, daily milking and cleaning were performed wearing a facemask connected to ambient air via flexible tubes to prevent adulteration of gas exchange measurement. Cows were milked at 0630 and $1630 \mathrm{~h}$. The BW was determined before and after the stay in the respiration chamber.

Heat production, fat oxidation, carbohydrate oxidation, and respiratory quotient were calculated as described previously (Chwalibog et al., 1996; Derno et al., 2013). For calculation of the respiratory quotient, which reflects the metabolism of absorbed nutrients, metabolic $\mathrm{CO}_{2}$ production (i.e., corrected for fermentative $\mathrm{CO}_{2}$ production) was used. Heat production was calculated according to Brouwer (1965) with total $\mathrm{CO}_{2}$ production as Brouwer's equation includes fermentative heat production (term for methane production).

\section{Blood Sampling}

All cows were equipped with a jugular vein catheter (Certofix Mono, B. Braun Melsungen AG, Melsungen, Germany), which was fixed with 2 stitches and a bandage (Optiplaste C, BSN medical S.A.S., Vibraye, France) and connected to $4 \mathrm{~m}$ of tubing (Original Perfusor Line, B. Braun Melsungen AG, Melsungen, Germany), to allow blood sampling from outside the chamber. After 1 wk of each treatment and during the stay in the respiration chamber, blood samples were taken at $0630,0830,1030,1530,1730$, and 1930 $\mathrm{h}$ through the catheter using potassium-EDTA and lithium-heparin monovettes $(9 \mathrm{~mL}$, Sarstedt AG \& Co., Nümbrecht, Germany).

\section{Sample Processing and Analyses}

Blood samples were immediately centrifuged at 1,500 $\times g$ at $4^{\circ} \mathrm{C}$ for $20 \mathrm{~min}$ and plasma aliquots were stored at $-80^{\circ} \mathrm{C}$. Cholesterol, glucose, triglycerides (TG), fatty acids, BHB, albumin, urea, and lactate concentrations were analyzed with an automatic enzymatic analyzer (ABX Pentra 400, Horiba Medical, Montpellier, France) using commercial kits (Glucose: Kit 553-230, cholesterol: Kit 553-127, all MTI Diagnostics, Idstein, Germany; TG: Kit A11A01640, ABX-Horiba Medical, Montpellier, France; fatty acids: Kit $600-215 \mathrm{~S}$ or Kit 434-91795/436-91995, all WAKO Chemicals GmbH, Neuss, Germany; BHB: Kit RB1007, urea: Kit LT-UR 0050 or 0010, all Labor \& Technik Eberhart Lehmann GmbH, Berlin, Germany; albumin: Kit A11A01664, lactate: Kit A11A01721, all Axon Lab AG, Reichenbach, Germany). Plasma TG, lactate, fatty acids, and glucose concentrations were analyzed in all samples, whereas cholesterol, albumin, BHB, and urea were only analyzed at $1030 \mathrm{~h}$ and not on the restrictive day of respiration measurements.

Glucagon and insulin in samples taken at 0630, 0830, and $1030 \mathrm{~h}$ were analyzed using commercial RIA (Kit RIA-1258 and 1257, DRG Instruments GmbH, Marburg, Germany). Both variables were only measured during the ad libitum day of respiration measurements.

Plasma flavonoid content in 0830-h samples was analyzed as described by Gohlke et al. (2013a). Plasma quercetin and quercetin metabolites kaempferol, tamarixetin, and isorhamnetin were measured; concentration values presented in this paper are total plasma flavonoids, calculated as the sum of concentrations of quercetin and its metabolites. 


\section{Statistical Analysis}

Data obtained from the measurements in respiration chambers were analyzed using SAS Institute Inc. (2014) with a mixed model including the fixed effects of diet (with or without rutin), feeding regimen (ad libitum or restrictive during the stay in respiration chamber only), the interaction between diet and feeding regimen as well as effect of order of treatment assignment (rutin or control TMR given first), and effect of period in which cows received different diets (rutin or control; Kaps and Lamberson, 2004). Individual effect of cow (subject) was included in the model as random.

Plasma parameters measured on one time point per day only (cholesterol, albumin, BHB, urea, and flavonoids) were analyzed with a mixed model including the fixed effects of diet, order of treatment assignment, periods, and effect of residence (respiration chamber or not). Individual effect of cow was included in the model as random.

Repeatedly measured plasma metabolites (fatty acids, TG, glucose, and lactate) were analyzed with a repeated measures ANOVA model that included effects of diet, feeding regimen, the interaction term between diet and feeding regimen, effects of orders, and period, residence, time of day (mornings, afternoons), and sampling time relative to supplementation (1-3) as well as interaction between time of day and relative time. Effect of repeatedly sampled cow was considered random.

Data for repeatedly (at 0630, 0830 and $1030 \mathrm{~h}$ ) measured plasma hormones (insulin and glucagon) were analyzed with another repeated measures ANOVA model that included effects of diet, order, residence, periods and effects of sampling time relative to supplementation. Effect of repeatedly sampled cow was considered random.

Variance structure for the repeated measures ANOVA models was variance components as it provided better (smaller) model fit parameters. Effects were considered significant at $P \leq 0.05$ and as a trend at $P \leq 0.1$. Data are presented as least squares means \pm standard error.

\section{RESULTS}

\section{Performance}

Average milk yield $(33.2 \pm 1.40 \mathrm{~kg} / \mathrm{d})$ and DMI $(21.6 \pm 0.61 \mathrm{~kg} / \mathrm{d})$ during the experimental period were not affected by rutin supplementation or feeding regimen. Milk components were not influenced by rutin supplementation and were $3.8 \pm 0.16 \%$ fat, $3.2 \pm 0.10 \%$ protein, and $4.9 \pm 0.05 \%$ lactose. The BW was lower $(P<0.001)$ after respiration measurements than before $(606 \pm 16$ vs. $625 \pm 16 \mathrm{~kg})$ and not influenced by rutin supplementation.

\section{Energy Expenditure}

Parameters of energy expenditure and gas exchange (Table 2), and in particular methane emission, were not affected by rutin supplementation but by feeding regimen $(P<0.05)$. Dry matter intake in the respiration chamber with ad libitum and restricted feeding, respectively, did not differ $(21.7$ vs. $21.6 \mathrm{~kg} / \mathrm{d}$; pooled $\mathrm{SE}=$ $0.40)$. No significant interaction effect of treatment by feeding regimen was observed on any of the variables.

Table 2. Parameters of gas exchange and energy expenditure during ad libitum and restricted feeding, and with and without (control) rutin supplementation (LSM)

\begin{tabular}{|c|c|c|c|c|c|c|c|}
\hline Item & \multicolumn{2}{|c|}{ Feeding regimen } & $P$-value & \multicolumn{2}{|c|}{ Treatment } & $P$-value & $\mathrm{PSE}^{2}$ \\
\hline $\mathrm{CH}_{4}$ production $(\mathrm{L} / \mathrm{d})$ & 612 & 531 & $<0.001$ & 570 & 573 & 0.753 & 14.7 \\
\hline $\mathrm{CO}_{2}$ production $^{3}(\mathrm{~L} / \mathrm{d})$ & 5,915 & 5,527 & 0.002 & 5,689 & 5,753 & 0.562 & 185.6 \\
\hline $\mathrm{O}_{2}$ consumption $(\mathrm{L} / \mathrm{d})$ & 7,079 & 6,817 & 0.064 & 6,902 & 6,994 & 0.498 & 174.1 \\
\hline Heat production/d $\left(\mathrm{kJ} / \mathrm{kg}\right.$ of $\left.\mathrm{BW}^{0.75}\right)$ & 1,183 & 1,155 & 0.136 & 1,163 & 1,174 & 0.550 & 15.8 \\
\hline $\mathrm{FOX}^{6}\left(\mathrm{~kJ} / \mathrm{kg}\right.$ of $\left.\mathrm{BW}^{0.75}\right)$ & 625 & 709 & $<0.001$ & 662 & 673 & 0.584 & 96.2 \\
\hline
\end{tabular}

${ }^{1}$ Residual feed removed at $0630 \mathrm{~h}$, followed by refeeding at $1630 \mathrm{~h}$.

${ }^{2} \mathrm{PSE}=$ pooled standard error.

${ }^{3}$ Metabolic $\mathrm{CO}_{2}$ (corrected for fermentative $\mathrm{CO}_{2}$ production).

${ }^{4} \mathrm{RQ}=$ respiratory quotient.

${ }^{5} \mathrm{COX}=$ carbohydrate oxidation.

${ }^{6} \mathrm{FOX}=$ fat oxidation. 
Table 3. Plasma metabolite, hormone concentrations, and plasma flavonoid levels with and without (control) rutin supplementation (LSM)

\begin{tabular}{|c|c|c|c|c|}
\hline \multirow[b]{2}{*}{ Item } & \multicolumn{2}{|c|}{ Treatment } & \multirow[b]{2}{*}{$P$-value } & \multirow[b]{2}{*}{$\mathrm{PSE}^{1}$} \\
\hline & Rutin & Control & & \\
\hline Fatty acids $(\mu \mathrm{mol} / \mathrm{L})$ & 166 & 148 & 0.142 & 8.9 \\
\hline $\mathrm{TG}^{2}(\mathrm{mmol} / \mathrm{L})$ & 0.14 & 0.13 & 0.211 & 0.003 \\
\hline Lactate $(\mathrm{mmol} / \mathrm{L})$ & 0.33 & 0.32 & 0.420 & 0.013 \\
\hline Glucose (mmol/L) & 3.55 & 3.47 & 0.067 & 0.028 \\
\hline $\operatorname{Albumin}(\mathrm{g} / \mathrm{L})$ & 33.2 & 31.9 & 0.013 & 0.86 \\
\hline $\mathrm{BHB}(\mathrm{mmol} / \mathrm{L})$ & 0.79 & 0.70 & 0.068 & 0.078 \\
\hline Cholesterol $(\mathrm{mmol} / \mathrm{L})$ & 4.91 & 5.12 & 0.654 & 0.492 \\
\hline Urea $(\mathrm{mmol} / \mathrm{L})$ & 4.95 & 4.53 & 0.204 & 0.364 \\
\hline Insulin $(\mu \mathrm{U} / \mathrm{mL})$ & 11.1 & 11.1 & 0.586 & 0.62 \\
\hline Glucagon (ng/L) & 126 & 131 & 0.760 & 3.1 \\
\hline Quercetin $(\mathrm{nmol} / \mathrm{L})$ & 35.6 & 5.4 & 0.003 & 8.98 \\
\hline
\end{tabular}

${ }^{1} \mathrm{PSE}=$ pooled standard error.

${ }^{2} \mathrm{TG}=$ triglycerides.

\section{Plasma Metabolites, Hormones, and Flavonoid Content}

Plasma fatty acid levels were higher $(P<0.001)$ under restricted $(203 \pm 11.6 \mu \mathrm{mol} / \mathrm{L})$ than under ad libitum $(109 \pm 6.7 \mu \mathrm{mol} / \mathrm{L})$ feed intake. Plasma fatty acid concentrations were not affected by rutin supplementation (Table 3).

Values of plasma TG were not affected by rutin supplementation (Table 3) or feeding. Lactate values were affected by order of treatment $(P=0.009)$ and were higher if rutin was given first $(0.36 \pm 0.012$ $\mathrm{mmol} / \mathrm{L})$ compared with control given first $(0.29 \pm$ $0.013 \mathrm{mmol} / \mathrm{L})$.

Plasma glucose concentrations tended to be higher $(P=0.067)$ under rutin supplementation (Table 3$)$. Plasma glucose tended $(P=0.054)$ to be affected by feeding regimen with lower values $(3.46 \pm 0.037$ $\mathrm{mmol} / \mathrm{L}$ ) under restricted feed intake than under ad libitum feeding $(3.56 \pm 0.021 \mathrm{mmol} / \mathrm{L})$.

Plasma albumin was higher $(P=0.013)$ under rutin supplementation than without (Table 3). The BHB values tended $(P=0.068)$ to be higher under rutin supplementation (Table 3). Plasma values of cholesterol and urea were not affected by rutin supplementation. Because we took blood samples only once on the day of respiration measurements under ad libitum feeding for cholesterol, albumin, BHB, and urea, it was not possible to estimate effects of feeding regimen for these parameters. Plasma insulin was not influenced by rutin supplementation (Table 3). Insulin values were influenced $(P=0.040)$ by order of treatments with higher values if rutin was given first $(12.5 \pm 0.57 \mu \mathrm{U} / \mathrm{mL})$ than if control was given first $(10.2 \pm 0.64 \mu \mathrm{U} / \mathrm{mL})$. Plasma glucagon was not influenced by rutin supplementation, but by order of treatments $(P=0.037)$, with higher values if rutin was given first $(134 \pm 2.9 \mathrm{ng} / \mathrm{L}$ vs. 122 $\pm 3.3 \mathrm{ng} / \mathrm{L})$.

Quercetin was the major flavonoid in plasma samples $1 \mathrm{~h}$ after rutin supplementation. Furthermore, minor levels of kaempferol and isorhamnetin were found, yet no tamarixetin could be detected. Total plasma flavonoid concentrations were higher $(P=0.003)$ during the period of rutin supplementation, whereas without rutin supplementation plasma flavonoid content was 7 times lower (Table 3).

Supplementation of ground buckwheat seeds did not increase total plasma flavonoids in comparison with TMR feeding only. Given that plasma flavonoid values did not reach detection level and we focused on flavonoid effects, we decided not to evaluate related results of respiration measurements and blood analyses.

\section{DISCUSSION}

The aim of our study was to assess possible beneficial effects of rutin in dairy cows in vivo with emphasis on energy metabolism, methane production, and production performance. Because the systemic availability of quercetin is much better after intraruminal application of rutin compared with quercetin aglycone (Berger et al., 2012), we wanted to investigate effects of oral rutin supplementation. To our knowledge, this is the first study to examine rutin effects when given orally in the pure form and contained in buckwheat seeds in lactating dairy cows.

Rutin trihydrate supplementation of $100 \mathrm{mg} / \mathrm{kg}$ of BW elevated total flavonoid levels in plasma by $600 \%$ with quercetin as the main metabolite. Indeed, total plasma flavonoid levels were comparably lower than in former studies with quercetin as rutin given intraruminally at $50 \mathrm{mg} / \mathrm{kg}$ of BW (Berger et al., 2012) or with 
quercetin as aglycone given intraduodenally at $100 \mathrm{mg} /$ $\mathrm{kg}$ of BW (Stoldt et al., 2015). The different levels of plasma flavonoids are most likely due to the different ways of flavonoid application and different stages of lactation of the cows examined. As discussed, capability for hepatic detoxification of absorbed flavonoids may differ in regard to the lactation stage (Stoldt et al., 2015). Production performance of cows was not altered by rutin supplementation. Improved milk yield or milk protein content, as reported for rutin (Guo et al., 2010) and intraduodenally administered quercetin (Gohlke et al., 2013b), could not be confirmed. Energy expenditure was not modified by rutin supplementation. Changes found in parameters related to energy metabolism indicate the metabolic shift toward fat oxidation as triggered by the feed restriction period, consistent with former studies (Derno et al., 2013). Because cows were fed ad libitum after the restriction period, they were able to catch up to their normal DMI so that total DMI did not differ between days with ad libitum or restrictive feeding.

Although flavonoids, including rutin and quercetin, were found to reduce rumen methane production in vitro by altering rumen microbiota (Oskoueian et al., 2013; Wang et al., 2013), rutin supplementation did not result in a reduced methane emission in our in vivo study. This is in accordance with observations of Berger et al. (2015), who found no effects of quercetin and rutin on in vitro methane production using the Hohenheimer gas test. Possibly, the residence time of rutin in rumen was too short or the rutin dose used in our experiment was not sufficient to suppress methanogens. It is noteworthy that relative flavonoid doses used in many in vitro studies were much higher than in our study and not feasible for animal studies. Although the differences found for plasma glucose concentrations were quite small, they tended to be higher under rutin supplementation. This is in contrast to findings in cows supplemented with quercetin intraduodenally (Gohlke et al., 2013b), where quercetin decreased plasma glucose. It is known that quercetin may affect glucose tolerance and insulin effects (Shao et al., 2013), but plasma insulin was not changed by flavonoid treatment.

Similar to midlactation cows under quercetin supplementation (Gohlke et al., 2013b) plasma BHB values tended to be higher under rutin supplementation. It is noteworthy that quercetin supplementation tended to decrease plasma BHB values in metabolically stressed periparturient dairy cows (Stoldt et al., 2015). Although within physiological range (Alberghina et al., 2011), plasma albumin values were higher under rutin supplementation, which is in contrast to our previous study (Stoldt et al., 2015). As it is established for carbohydrate metabolism that flavonoids exert their effects differently under different health conditions (Shao et al., 2013; Xu et al., 2014), the influence of cow health and state of lactation on the effects of flavonoid supplementation should not be underestimated and needs to be clarified. Effects of order of treatment found for lactate, insulin, and glucagon are not easy to interpret, because no rutin effects were found for these parameters; thus, a carry-over effect from rutin to control treatment is unlikely.

Oral supplementation of ground buckwheat seeds was not sufficient to increase total plasma flavonoids above the detection limit. We assume low digestibility of the buckwheat seeds was a possible cause, because a recognizable amount of the seed particles was found unmodified in cow feces despite milling. Others (Kälber et al., 2012, 2013) have reported feeding of buckwheat as silage, which seems to be more digestible and suitable as dietary component. Whether buckwheat silage feeding increases plasma flavonoid level remains to be investigated.

Taken together, we found that feeding of rutin increased plasma quercetin content in dairy cows, but not to the same extent as found for intraduodenal quercetin aglycone supplementation (Gohlke et al., 2013a; Stoldt et al., 2015). The present and previous results indicate that the absolute concentrations of quercetin in cow plasma, as well as health conditions and the stage of lactation of the cow, influence the specificity of quercetin effects on energy metabolism and production performance. Effects of quercetin are contradictory under different settings, and health-promoting properties of quercetin seem to be more pronounced in cows under challenged metabolic health conditions (Stoldt et al., 2015), such as in transition cows. However, we could not confirm in vivo earlier reports of in vitro effects of flavonoids on rumen methane production (Leiber et al., 2012). Feeding rutin or buckwheat silage to metabolically challenged cows is an interesting approach for research, but requires further study.

\section{CONCLUSIONS}

In our study, we could not confirm previously shown in vitro reductions of rumen methane production by flavonoids using an oral dose of rutin at $100 \mathrm{mg} / \mathrm{kg}$ of BW in vivo, presumably due to an insufficient local flavonoid concentration in the rumen. Buckwheat seeds do not appear to be a good source for quercetin supplementation in dairy cows. Furthermore, metabolic effects of flavonoids seem to be more distinct in metabolically stressed than in healthy cows. 


\section{ACKNOWLEDGMENTS}

The authors are grateful to P. Schulz (Institute for Animal Nutrition and Physiology, Christian-AlbrechtsUniversity of Kiel, Germany) as well as S. Dwars, K. Grot, C. Arlt, and S. Görs (Leibniz Institute for Farm Animal Biology, Institute of Nutritional Physiology "Oskar Kellner") for excellent laboratory assistance. B. Stabenow, K.-D. Witt and his team, and D. Oswald, T. Lenke, A. Schulz, and K. Pilz of the "Tiertechnikum" (Leibniz Institute for Farm Animal Biology; Institute of Nutritional Physiology "Oskar Kellner") are gratefully acknowledged for assistance with animal care and rutin feeding. This work is part of the joint research project AgroClustEr FoCus - Food Chain Plus, and was financially supported by the Federal Ministry of Education and Research, Germany, under the funding initiative "Kompetenznetze der Agrar- und Ernährungsforschung" (BMBF grant number 0315538B).

\section{REFERENCES}

Alberghina, D., C. Giannetto, I. Vazzana, V. Ferrantelli, and G. Piccione. 2011. Reference intervals for total protein concentration, serum protein fractions, and albumin/globulin ratios in clinically healthy dairy cows. J. Vet. Diagn. Invest. 23:111-114.

Amelchanka, S. L., M. Kreuzer, and F. Leiber. 2010. Utility of buckwheat (Fagopyrum esculentum Moench) as feed: Effects of forage and grain on in vitro ruminal fermentation and performance of dairy cows. Anim. Feed Sci. Technol. 155:111-121. http://dx.doi. org/10.1016/j.anifeedsci.2009.10.007.

Berger, L. M., R. Blank, F. Zorn, S. Wein, C. C. Metges, and S. Wolffram. 2015. Ruminal degradation of quercetin and its influence on fermentation in ruminants. J. Dairy Sci. 98:5688-5698. http://dx.doi.org/10.3168/jds.2015-9633.

Berger, L. M., S. Wein, R. Blank, C. C. Metges, and S. Wolffram, 2012. Bioavailability of the flavonol quercetin in cows after intraruminal application of quercetin aglycone and rutin. J. Dairy Sci. 95:5047-5055. http://dx.doi.org/10.3168/jds.2012-5439.

Brouwer, E. 1965. Report of sub-committee on constants and factors. Pages 441-443 in Energy Metabolism of Farm Animals. K. L. Blaxter, ed. Academic Press, London, UK.

Chwalibog, A., K. Jensen, and G. Thorbek. 1996. Oxidation of nutrients in bull calves treated with $\beta$-adrenergic agonists. Arch. Tierenahr. 49:255-261.

Derno, M., H. G. Elsner, E.-A. Paetow, H. Scholze, and M. Schweigel. 2009. Technical note: A new facility for continuous respiration measurements in lactating cows. J. Dairy Sci. 92:2804-2808. http://dx.doi.org/10.3168/jds.2008-1839.

Derno, M., G. Nürnberg, P. Schön, A. Schwarm, M. Röntgen, H. M. Hammon, C. C. Metges, R. M. Bruckmaier, and B. Kuhla. 2013. Short-term feed intake is regulated by macronutrient oxidation in lactating Holstein cows. J. Dairy Sci. 96:971-980. http://dx.doi. org $/ 10.3168 /$ jds. $2012-5727$.

Etim, N. N., E. E. A. Offiong, and U. A. Ukpanah. 2013. Farm animals: Culprits and victims of global warming and climate change. Am. J. Adv. Agric. Res. 1:10-24.

Fabjan, N., J. Rode, I. J. Kosir, Z. H. Wang, Z. Zhang, and I. Kreft. 2003. Tartary buckwheat (Fagopyrum tartaricum Gaertn.) as a source of dietary rutin and quercitrin. J. Agric. Food Chem. 51:6452-6455. http://dx.doi.org/10.1021/jf034543e.

Formica, J. V., and W. Regelson. 1995. Review of the biology of quercetin and related bioflavonoids. Food Chem. Toxicol. 33:10611080. http://dx.doi.org/10.1016/0278-6915(95)00077-1.
Galleano, M., V. Calabro, P. D. Prince, M. C. Litterio, B. Piotrkowski, M. A. Vazquez-Prieto, R. M. Miatello, P. I. Oteiza, and C. G. Fraga. 2012. Flavonoids and metabolic syndrome. Ann. N. Y. Acad. Sci. 1259:87-94. http://dx.doi.org/10.1111/j.1749-6632.2012.06511.x.

GfE (German Society of Nutrition Physiology). 2004. Ausschuss für Bedarfsnormen der Gesellschaft für Ernährungsphysiologie, Nummer 13. Empfehlungen zur Energie- und Nährstoffversorgung der Milchkühe und Aufzuchtrinder (Recommended Energy and Nutrient Supply for Dairy Cows and Growing Cattle). DLG-Verlag, Frankfurt am Main, Germany.

Gohlke, A., C. J. Ingelmann, G. Nürnberg, A. Starke, S. Wolffram, and C. C. Metges. 2013a. Bioavailability of quercetin from its aglycone and its glucorhamnoside rutin in lactating dairy cows after intraduodenal administration. J. Dairy Sci. 96:2303-2313. http:// dx.doi.org/10.3168/jds.2012-6234.

Gohlke, A., C. J. Ingelmann, G. Nürnberg, J. M. Weitzel, H. M. Hammon, S. Görs, A. Starke, S. Wolffram, and C. C. Metges. 2013b. Influence of 4-week intraduodenal supplementation of quercetin on performance, glucose metabolism, and mRNA abundance of genes related to glucose metabolism and antioxidative status in dairy cows. J. Dairy Sci. 96:6986-7000. http://dx.doi.org/10.3168/ jds.2013-6852.

Guo, X. D., Q. Y. Diao, Y. Tu, G. L. Yan, N. F. Zhang, K. D. Deng, C. F. Ju, G. Q. Zhao, Y. Y. Wang, X. W. Gu, Z. Y. Lu, and X. J. Wang. 2010. Effect of rutin supplementation on lactation performance and serum parameters in lactating Chinese Holstein cows. Sci. Agric. Sin. 43:5137-5146.

Hoek-van den Hil, E. F., J. Keijer, A. Bunschoten, J. J. M. Vervoort, B. Stankova, M. Bekkenkamp, L. Herreman, D. Venema, P. C. H. Hollman, E. Tvrzicka, I. M. C. M. Rietjens, and E. M. van Schothorst. 2013. Quercetin induces hepatic lipid omega-oxidation and lowers serum lipid levels in mice. PLoS ONE 8:e51588 http:// dx.doi.org/10.1371/journal.pone.0051588.

Kälber, T., M. Kreuzer, and F. Leiber. 2012. Silages containing buckwheat and chicory: Quality, digestibility and nitrogen utilization by lactating cows. Arch. Anim. Nutr. 66:50-65. http://dx.doi.org/ 10.1080/1745039X.2011.630213.

Kälber, T., M. Kreuzer, and F. Leiber. 2013. Effect of feeding buckwheat and chicory silages on fatty acid profile and cheese-making properties of milk from dairy cows. J. Dairy Res. 80:81-88. http:// dx.doi.org/10.1017/S0022029912000647.

Kaps, M., and W. R. Lamberson. 2004. Biostatistics for Animal Science. CABI Publishing, Wallingford, U.K.

Leiber, F., C. Kunz, and M. Kreuzer. 2012. Influence of different morphological parts of buckwheat (Fagopyrum esculentum) and its major secondary metabolite rutin on rumen fermentation in vitro. Czech J. Anim. Sci. 57:10-18.

Materska, M. 2008. Quercetin and its derivatives: Chemical structure and bioactivity - A review. Pol. J. Food Nutr. Sci. 58:407-413.

Naumann, C., and R. Bassler. 1993. Methodenbuch Band III: Die chemische Untersuchung von Futtermitteln. (Method Book III: The chemical analysis of feedstuffs). VDLUFA-Verlag, Darmstadt, Germany.

Niderkorn, V., and D. Macheboeuf. 2014. Identification of bioactive grassland plants for reducing enteric methane production and rumen proteolysis using an in vitro screening assay. Anim. Prod. Sci. 54:1805-1809. http://dx.doi.org/10.1071/AN14168.

Nijveldt, R. J., E. van Nood, D. E. C. van Hoorn, P. G. Boelens, K. van Norren, and P. M. van Leeuwen. 2001. Flavonoids: A review of probable mechanisms of action and potential applications. Am. J. Clin. Nutr. 74:418-425.

Oskoueian, E., N. Abdullah, and A. Oskoueian. 2013. Effects of flavonoids on rumen fermentation activity, methane production, and microbial population. BioMed Res. Int. 2013:349129. http:// dx.doi.org/10.1155/2013/349129.

Panchal, S. K., H. Poudyal, T. V. Arumugam, and L. Brown. 2011. Rutin attenuates metabolic changes, nonalcoholic steatohepatitis, and cardiovascular remodeling in high-carbohydrate, high-fat diet-fed rats. J. Nutr. 141:1062-1069. http://dx.doi.org/10.3945/ jn.111.137877. 
Pitesky, M. E., K. R. Stackhouse, and F. M. Mitloehner. 2009. Clearing the air: Livestock's contribution to climate change. Adv. Agron. 103:1-40. http://dx.doi.org/10.1016/S0065-2113(09)03001-6.

Rochfort, S., A. J. Parker, and F. R. Dunshea. 2008. Plant bioactives for ruminant health and productivity. Phytochemistry 69:299-322. phytochem.2007.08.017.

Santra, A., A. Saikia, and K. K. Baruah. 2012. Scope of rumen manipulation using medicinal plants to mitigate methane production. J. Pharmacogn. 3:115-120.

SAS Institute Inc. 2014. SAS OnlineDoc Version 9.3. SAS Institute Inc., Cary, NC.

Seradj, A. R., L. Abecia, J. Crespo, D. Villalba, M. Fondevila, and J. Balcells. 2014. The effect of Bioflavex and its pure flavonoid components on in vitro fermentation parameters and methane production in rumen fluid from steers given high concentrate diets. Anim. Feed Sci. Technol. 197:85-91. http://dx.doi.org/10.1016/j. anifeedsci.2014.08.013.

Shao, L., K. Liu, F. Huang, X. D. Guo, M. Wang, and B. L. Liu. 2013. Opposite effects of quercetin, luteolin, and epigallocatechin gallate on insulin sensitivity under normal and inflammatory conditions in mice. Inflammation 36:1-14. http://dx.doi.org/10.1007/s10753 012-9514-x.

Stoldt, A. K., M. Derno, G. Nürnberg, J. M. Weitzel, W. Otten, A. Starke, S. Wolffram, and C. C. Metges. 2015. A 6-wk intraduodenal supplementation of quercetin reduces indicators of liver damage in periparturient dairy cows. J. Dairy Sci. 98:4509-4520. http://dx.doi.org/10.3168/jds.2014-9053.

Wang, D. S., J. L. Huang, Z. H. Zhang, X. J. Tian, H. Huang, Y. Z. $\mathrm{Yu}$, G. H. Zhang, J. N. Ding, and R. L. Huang. 2013. Influences of Portulaca oleracea extracts on in vitro methane emissions and rumen fermentation of forage. J. Food Agric. Environ. 11:483-488.

Wein, S., and S. Wolffram. 2014. Concomitant intake of quercetin with a grain-based diet acutely lowers postprandial plasma glucose and lipid concentrations in pigs. BioMed Res. Int. 2014:748742. http:// dx.doi.org/10.1155/2014/748742.

Xu, M., J. J. Hu, W. W. Zhao, X. J. Gao, C. H. Jiang, K. Liu, B. L. Liu, and F. Huang. 2014. Quercetin differently regulates insulin-mediated glucose transporter 4 translocation under basal and inflammatory conditions in adipocytes. Mol. Nutr. Food Res. 58:931-941. http://dx.doi.org/10.1002/mnfr.201300510. 